\begin{tabular}{|c|c|}
\hline Title & $\begin{array}{l}\text { In Situ Study of Ultrathin Film Formation on A u(111) Surface in Propylene Carbonate by Scanning Tunneling } \\
\text { Microscopy under Potential Control }\end{array}$ \\
\hline Author(s) & Saito, Toshiya; U osaki, Kohei \\
\hline Citation & $\begin{array}{l}\text { Journal of The Electrochemical Society, 149(8), E286-E291 } \\
\text { https://doi.org/10.1149/1.1488917 }\end{array}$ \\
\hline Issue Date & 2002 \\
\hline Doc URL & http:/hdl .handle.net/2115/50229 \\
\hline Rights & $\begin{array}{l}\text { (1) The Electrochemical Society, Inc. 2002. All rights reserved. Except as provided under U.S. copyright law, this work } \\
\text { may not be reproduced, resold, distributed, or modified without the express permission of The Electrochemical Society } \\
\text { (ECS). The archival version of this work was published in J. Electrochem. Soc. } 2002 \text { volume 149, issue 8, E286-E291. }\end{array}$ \\
\hline Type & article \\
\hline File Information & JES149-8_E286-E291.pdf \\
\hline
\end{tabular}

Instructions for use 


\section{In Situ Study of Ultrathin Film Formation on Au(111) Surface in Propylene Carbonate by Scanning Tunneling Microscopy under Potential Control}

Toshiya Saito and Kohei Uosaki

J. Electrochem. Soc. 2002, Volume 149, Issue 8, Pages E286-E291. doi: $10.1149 / 1.1488917$

Email alerting Receive free email alerts when new articles cite this article - sign up in the service box at the top right corner of the article or click here 


\section{(4ters) In Situ Study of Ultrathin Film Formation on Au(111) Surface
in Propylene Carbonate by Scanning Tunneling
Microscopy under Potential Control}

Toshiya Saito and Kohei Uosaki*,z

Physical Chemistry Laboratory, Division of Chemistry, Graduate School of Science, Hokkaido University, Sapporo 060-0810, Japan

In situ scanning tunneling microscopy (STM) revealed the formation of an adsorbate layer on Au(111) in propylene carbonate (PC) containing $0.1 \mathrm{M} \mathrm{LiClO}_{4}$. The structure of the adsorbate layer was affected by the electrode potential. A comparison with the differential capacitance measurement result suggests that the surface charge of the electrode played an important role. At potentials more positive than the potential of the zero charge (pzc), the growth of the island-like structure on the Au(111) surface was observed. As very similar STM images were obtained in neat PC, it was concluded that the adsorbate layer in this potential region consisted of PC molecules. Both at the pzc and at potentials more negative than the pzc, a herringbone structure was observed showing the reconstructed $\mathrm{Au}(111)$ surface. While the surface was uniform at the pzc, there were small holes on the terrace at the latter potentials. The holes were considered to be a defect of a film covering the Au(111) surface with a uniform thickness. The possible adsorbate at the pzc and at potentials more negative than the pzc also consisted of PC molecules, although the adsorbate structure was not clear.

(C) 2002 The Electrochemical Society. [DOI: 10.1149/1.1488917] All rights reserved.

Manuscript submitted October 2, 2001; revised manuscript received February 5, 2002. Available electronically June 17, 2002.

The electrochemical deposition and dissolution of lithium in an aprotic solvent has attracted much attention because of the industrial significance in its application to lithium secondary batteries. Although the lithium metal rechargeable battery is very attractive for the reduction of weight, and therefore, an energy/power density improvement, the relatively low reversibility of the deposition and dissolution of lithium metal inhibits the practical use of the Li metal battery. Many studies on lithium deposition and dissolution have been carried out to improve the reversibility and to prevent the growth of dendrites under various conditions. Due to high activity of lithium metal, the surface of lithium in an electrolyte solution is covered with a native oxide film or reduced products of the electrolyte solution and/or impurities. ${ }^{1}$ The surface film thus formed is believed to play important roles in the lithium deposition and dissolution. The chemical composition and formation process of the surface film on lithium metal have been studied in various electrolyte solutions ${ }^{2}$ such as propylene carbonate $(\mathrm{PC}),{ }^{3} \gamma$-butyrolactone, ${ }^{4,5}$ and 1,3-dioxolane ${ }^{6}$ using various techniques including electrochemical methods, X-ray photoelectron spectroscopy, Fourier transformed infrared spectroscopy.

Alkyl carbonates, such as PC and ethylene carbonate (EC), react with lithium and form a surface film consisting of $\mathrm{ROCO}_{2} \mathrm{Li}$ on the Li metal surface. ${ }^{3}$ Esters such as $\gamma$-butyrolactone and ethers such as tetrahydrofuran react with lithium and form lithium carboxylate species $^{4,5}$ and lithium alkoxide, ${ }^{7}$ respectively. Impurities, which are unavoidably contained in solvents, also react with lithium and may play important roles in the surface film formation. Water, which is always contained in a nonaqueous solvent, is dissociated and generates hydrogen gas. The remaining hydroxide ion reacts and forms lithium hydroxide or oxide on the lithium surface. The reaction products such as lithium hydroxide or lithium oxide precipitate on the $\mathrm{Li}$ surface. ${ }^{3-5,7,8} \mathrm{HF}$, which is contained as an impurity in the electrolyte salts like $\mathrm{LiPF}_{6}$ and $\mathrm{LiBF}_{4}$, forms an $\mathrm{LiF}$ layer on the $\mathrm{Li}$ metal. $^{8-11}$

Scanning probe microscopy (SPM), such as scanning tunneling microscopy (STM) and atomic force microscopy (AFM), has become a powerful method to investigate the fundamental processes on electrode surfaces with atomic/molecular resolution. Electrochemical STM and AFM have been applied by many research groups for many electrochemical systems mainly in aqueous solutions. ${ }^{12}$ We have also employed STM and AFM to investigate

\footnotetext{
* Electrochemical Society Active Member

z E-mail: uosaki@pcl.sci.hokudai.ac.jp
}

various electrochemical processes including $\mathrm{Pt}^{13}$ and $\mathrm{Pd}^{14-17}$ deposition on $\mathrm{Au}(111)$ and $\mathrm{Au}(100)$ electrodes, $\mathrm{Cu}$ deposition on the $\mathrm{GaAs}(100)$ electrode, ${ }^{18}$ and dissolution of $\mathrm{Au}(111)^{19}$ and $\mathrm{Au}(100){ }^{20}$

The application of SPM for nonaqueous systems is still limited compared with that for aqueous systems. We have successfully monitored the self-assembly process of alkanethiols in heptane on gold $^{21,22}$ and the two-dimensional crystal formation of an alkane on a gold surface in neat alkane by STM with molecular resolution. ${ }^{23-25}$ It is very natural to apply in situ SPM to study processes at the lithium electrode. Morphology changes in the lithium surface during the dissolution/deposition cycle under several conditions have been investigated by in situ electrochemical SPM. ${ }^{26-28}$ Most of these studies were, however, carried out within sub- $\mu \mathrm{m}$ resolution, which is far from the atomic scale, and therefore, elucidation of the electrochemical processes on an atomic level is not possible. There are several reasons why SPM studies for the processes in nonaqueous solvents such as the Li deposition/dissolution are difficult. In many cases, a glove box is required to avoid the influence of water and oxygen because the redox potentials of the processes such as alkali metal deposition/dissolution are more negative than those for the reduction of water and oxygen and, moreover, even the reduction of the solvent itself may take place at such a negative potential.

Although many organic solvents such as PC, dimethyl sulfoxide, tetrahydrofuran, and dimethylformamide, have been used as a solvent for electrochemical studies, PC is one of the best candidates to be used as a solvent for a lithium metal secondary battery because of its wide temperature range as a liquid $\left(\mathrm{mp}-48.8^{\circ} \mathrm{C}\right.$, bp $\left.242^{\circ} \mathrm{C}\right),{ }^{29}$ relatively high dielectric constant $(66.14),{ }^{29}$ large dipole moment $(4.94 \mathrm{D}),{ }^{30}$ and wide potential window, particularly in the negative potential region. ${ }^{31}$ Actually, several papers for the investigation of the lithium deposition/dissolution processes in PC have been published. ${ }^{3,26,27,32-38}$ Although noble metals are less reactive than alkali metals the reduction of the solvent, anion, and water leading to a film formation may take place even on these electrodes in the very negative potential region. ${ }^{39}$ These processes on noble metal electrodes can be considered as model reactions for the surface film formation on a lithium electrode. Here, we carried out in situ electrochemical STM observations of the Au(111) electrode in PC solution containing $\mathrm{LiClO}_{4}$. The initial stage of the surface film formation is discussed based on the STM observations as well as the results of an electrochemical study such as cyclic voltammetry (CV) and differential capacitance measurements. 


\section{Experimental}

A gold single crystal bead was prepared by Clavilier's method ${ }^{40}$ from a gold wire (Tanaka, 99.99\% purity) and was cut in parallel to the (111) facet. The (111) face was polished with a diamond slurry down to $0.5 \mu \mathrm{m}$. The crystal was then annealed in an electric furnace at $850^{\circ} \mathrm{C}$ for $12 \mathrm{~h}$ under an $\mathrm{Ar}$ atmosphere. Prior to each experiment, the gold single crystal was annealed by a gas flame for a few minutes and cooled under an Ar gas stream. To avoid the surface contamination, the annealed gold was put in a glass container which contained pure hexane.

Lithium wire (Johnson-Matthey, 99.9\% purity) was cut and washed several times with hexane under an Ar environment before use as the reference electrode. Platinum wire (Tanaka, $99.99 \%$ purity) was used as the counter electrode.

Both neat PC and a PC solution containing $0.1 \mathrm{M} \mathrm{LiClO}_{4}$ were purchased from Tomiyama Chemicals (lithium battery grade). They contained less than $20 \mathrm{ppm}$ of water and were stored in an Ar filled glove box (VAC, Nexus 2000 system) to avoid the dissolution of water and oxygen into the solutions and used without further purification. The PC solution containing the $1 \mathrm{mM} \mathrm{LiClO}_{4}$ used for the capacitance measurement was prepared by diluting the PC solution containing $0.1 \mathrm{M} \mathrm{LiClO}_{4}$ with the neat $\mathrm{PC}$ in the glove box.

The STM measurements were carried out in the Ar filled glove box using a Nanoscope E control unit (Digital Instrument) and a PicoSPM scanning unit (Molecular Imaging). The scanning unit and a homemade vibration isolator were placed in the glove box, but the control unit was placed outside the glove box. The scanning unit was electronically connected to the control unit through an airtight connector on the side of the glove box. The STM tips were mechanically cut $20 \% \mathrm{Ir}-\mathrm{Pt}$ wire $(\phi=0.3 \mathrm{~mm})$. The tips for electrochemical capacitor-STM measurement were coated with Apiezon wax but the STM observation in neat PC was carried out using an uncoated tip. The Ar gas in the glove box was circulated through catalysts, which removed the oxygen and water. The oxygen concentration in the glove box was kept below $1 \mathrm{ppm}$, typically 0.1-0.2 ppm. The dew-point temperature in the glove box was less than the lower limit of a hygrometer, i.e., below $-100^{\circ} \mathrm{C}$. The Ar circulation blower and a vacuum pump for controlling the inner pressure of the glove box were stopped during the STM measurements. The oxygen concentration in the glove box became a few parts per million (ppm) at most $5 \mathrm{ppm}$, even $12 \mathrm{~h}$ after the STM experiment without any Ar circulation. The water concentration was still under the lower limit of hygrometer after the STM observations.

CV was carried out also in the glove box using a threecompartment glass cell. The electrochemical potential was controlled by a potentiostat (Hokuto Denko, HA-151) and the external potential was provided by a function generator (Hokuto Denko, HB111). The $\mathrm{Au}(111)$ electrode was contacted to the electrolyte solution under potential control and the potential scan was started within a few min after the contact.

A potentiostat (Toho Technology Research, model 2001), a frequency response analyzer (FRA, NF Electronic Instruments, S-5720B) and a personal computer (NEC, PC-9801) were used for the differential capacitance measurement. The measurement was carried out in a polyethylene bag, into which high purity Ar gas was blown for purging the air and maintaining the Ar atmosphere. The oxygen and water concentrations in the polyethylene bag were not monitored. A sine wave $\left(10 \mathrm{mV}_{\mathrm{p}-\mathrm{p}}, 5 \sim 50 \mathrm{~Hz}\right)$ with a direct current (dc) offset was generated by the FRA controlled by the computer via a GP-IB and was fed into the potentiostat. The electrolyte solutions were prepared and stored in the glove box. They were placed in a tightly capped glass container and transferred to the polyethylene bag. The annealed electrode was also transferred to the bag. Ar gas was blown into the for bag at least $30 \mathrm{~min}$ after the electrode transfer into the bag for minimizing the effect of oxygen and water. Each capacitance measurement took about 10 min. Essentially the same CV as that in the glove box was obtained in the

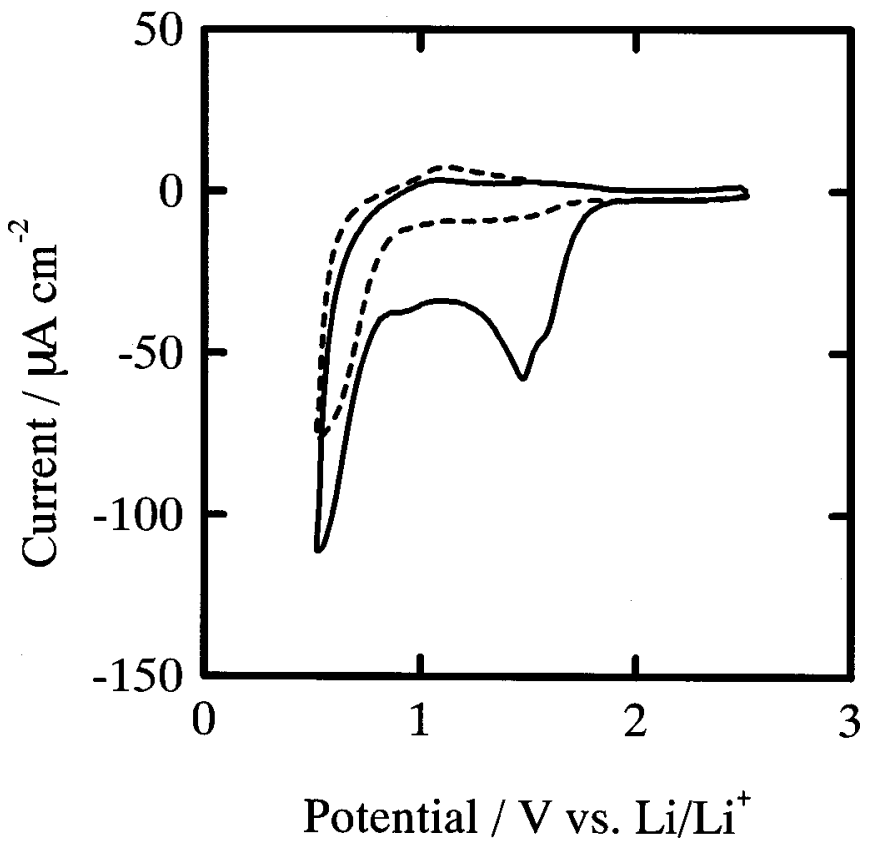

Figure 1. Cyclic voltammogram of $\mathrm{Au}(111)$ electrode in the $\mathrm{PC}$ solution containing $0.1 \mathrm{M} \mathrm{LiClO}_{4}$ at $50 \mathrm{mV} / \mathrm{s}$. The $\mathrm{Au}(111)$ electrode was immersed at $2.50 \mathrm{~V}$ and the results of the initial two cycles are shown. The first and second cycles are shown by solid and broken lines, respectively.

polyethylene bag, showing the effects of oxygen and water were not serious for the measurements in the polyethylene bag.

\section{Results}

Electrochemical characteristics.-Figure 1 shows a cyclic voltammogram of an $\mathrm{Au}(111)$ electrode for the first two potential cycles after the $\mathrm{Au}(111)$ electrode was immersed in a PC solution containing $0.1 \mathrm{M} \mathrm{LiClO}_{4}$ at $2.50 \mathrm{~V}$ where neither a cathodic nor an anodic current flowed. In the first cycle (solid line), a cathodic current started to flow from around $1.8 \mathrm{~V}$ and a cathodic peak was observed around $1.5 \mathrm{~V}$. About $30-40 \mu \mathrm{A} / \mathrm{cm}^{2}$ of cathodic current flowed between 1.1 and $0.8 \mathrm{~V}$ and then the cathodic current significantly increased as the potential became more negative than $0.8 \mathrm{~V}$. An anodic current of a few $\mu \mathrm{A} / \mathrm{cm}^{2}$ flowed in the positive scan direction and small positive peak was found around 1.1 V. In the second cycle (broken line), the cathodic current started to flow again from around $1.8 \mathrm{~V}$ but no cathodic peak was observed and the limiting current was much less than that observed in the first cycle $\left(\sim 10 \mu \mathrm{A} / \mathrm{cm}^{2}\right)$. In the positive scan direction, small but a broad anodic current peak was observed at $1.2 \mathrm{~V}$. Although Aurbach et al. reported that the reduction peaks of water and oxygen were observed at 1.2 and $2.0 \mathrm{~V}$, respectively, in a PC solution containing 0.2 $\mathrm{M} \mathrm{LiAsF}_{6}$ and these peaks became smaller in the second and subsequent cycles as a result of the formation of a surface film of a reductive product of the electrolyte solution, ${ }^{39}$ no faradaic current was observed at potentials more positive than $1.8 \mathrm{~V}$ in the present study as shown in Fig. 1. This result confirms that oxygen was not contained in the solution and the onset potential for water reduction was about $1.8 \mathrm{~V}$. The cathodic current observed between 1.5 and 1.0 $\mathrm{V}$ and the one at potentials more negative than $1.0 \mathrm{~V}$ were considered to be due to the reduction of solvent and under potential deposition of lithium, respectively, although the reduction of solvent and/or anion are also contained in the current at potentials more negative than $1.0 \mathrm{~V}^{39}$ The small anodic peak at $1.1 \mathrm{~V}$ should be due to desorption of lithium. ${ }^{39}$

Figure 2 shows the potential dependence of the differential capacitance of the $\mathrm{Au}(111)$ electrode in PC solutions containing $1 \mathrm{mM}$ (solid line) and $0.1 \mathrm{M}$ (broken line) $\mathrm{LiClO}_{4}$ between 1.80 and 3.00 


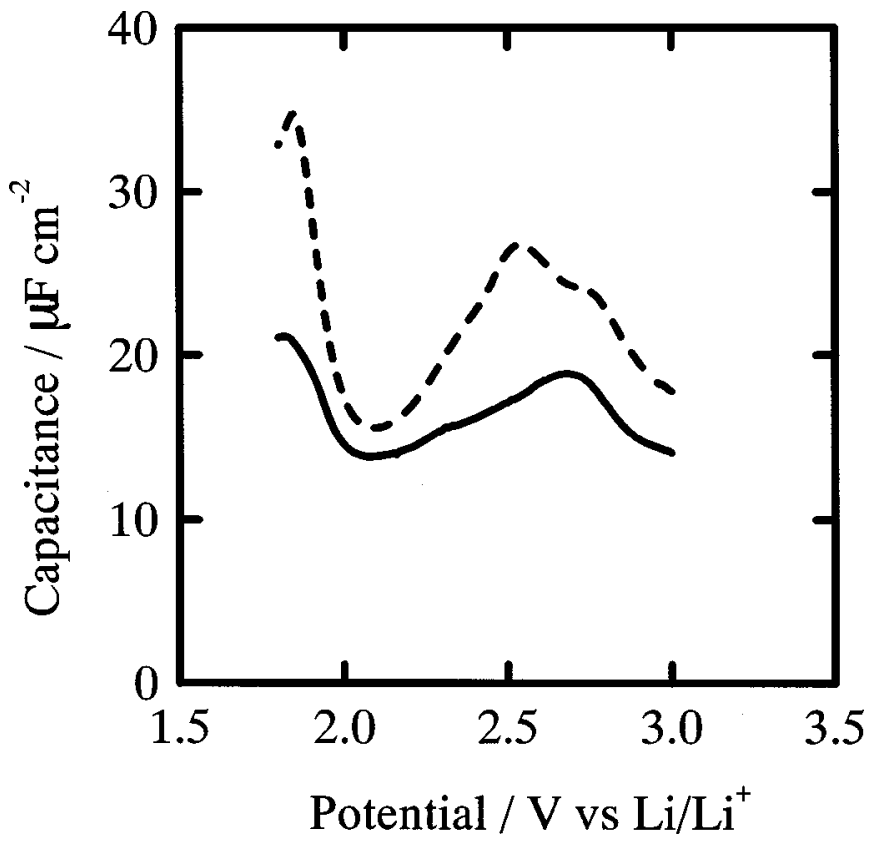

Figure 2. Potential dependence of differential capacitance of $\mathrm{Au}(111)$ in $\mathrm{PC}$ solutions containing $1 \mathrm{mM}$ (solid line) and $0.1 \mathrm{M}$ (broken line) $\mathrm{LiClO}_{4}$.

V. Essentially, the same features were observed. The difference capacitance increased as the potential became negative from $3.0 \mathrm{~V}$ and reached a maximum at 2.7 and $2.5 \mathrm{~V}$ in the $1 \mathrm{mM}$ and $0.1 \mathrm{M} \mathrm{LiClO}_{4}$ PC solutions, respectively. The capacitance then decreased with potential, reached a minimum at $2.09 \mathrm{~V}$, increased again, and reached maximum around $1.85 \mathrm{~V}$ in both solutions. The potential of the minimum capacitance should correspond to the potential of zero charge (pzc). ${ }^{41}$

Electrochemical STM measurements.-After confirming that a clean gold surface was exposed under the Ar atmosphere, the electrolyte solution was injected into the STM cell while keeping the potential of the gold electrode at $2.50 \mathrm{~V}\left(v s . \mathrm{Li} / \mathrm{Li}^{+}\right)$.

Figure 3 shows the sequentially obtained STM images of the gold surface at $2.50 \mathrm{~V}$. Although the wide flat terraces separated by monoatomic $(0.25 \mathrm{~nm})$ height step were observed for the initial 7 min after the injection of the solution (Fig. 3a), the gold terrace became slightly rough $16 \mathrm{~min}$ after the injection (Fig. 3b). Small nuclei appeared randomly all over the terraces. These nuclei seemed to be stretched in the horizontal direction (Fig. 3b). These nuclei grew into island-like structures with time as observed in an image captured $30 \mathrm{~min}$ after the injection (Fig. 3c). A two-dimensional growth of these islands was further observed with time and they merged with each other (Fig. 3d, e). The heights of these islands were $c a .0 .17 \mathrm{~nm}$ with the distribution of $0.15-0.25 \mathrm{~nm}$ (Fig. 3f). Uniform island-like structures were also observed on all the terraces after the sequential observation of the STM images and no difference in the density and dimensions of the island-like structures were found whether the position was scanned with STM tip or not, showing the no effect of the tip scanning on the image. Furthermore, no influence was observed when the tip potential was changed between 2.0 and $2.9 \mathrm{~V}$ after capturing Fig. 3f.

Figure 4 shows an STM image of the $\mathrm{Au}(111)$ surface captured at $2.09 \mathrm{~V}$, i.e., pzc, $100 \mathrm{~min}$ after the injection of the solution at this potential. In contrast to the result at $2.50 \mathrm{~V}$, where island-like structures were observed in less than $30 \mathrm{~min}$ after the solution injection, no island-like structure was found on the $\mathrm{Au}(111)$ surface at this potential even after $100 \mathrm{~min}$. No nucleation was observed in the STM observation at $+2.09 \mathrm{~V}$. Winding paired stripes were found on the terrace of the $\mathrm{Au}(111)$ surface and these stripes formed a her-
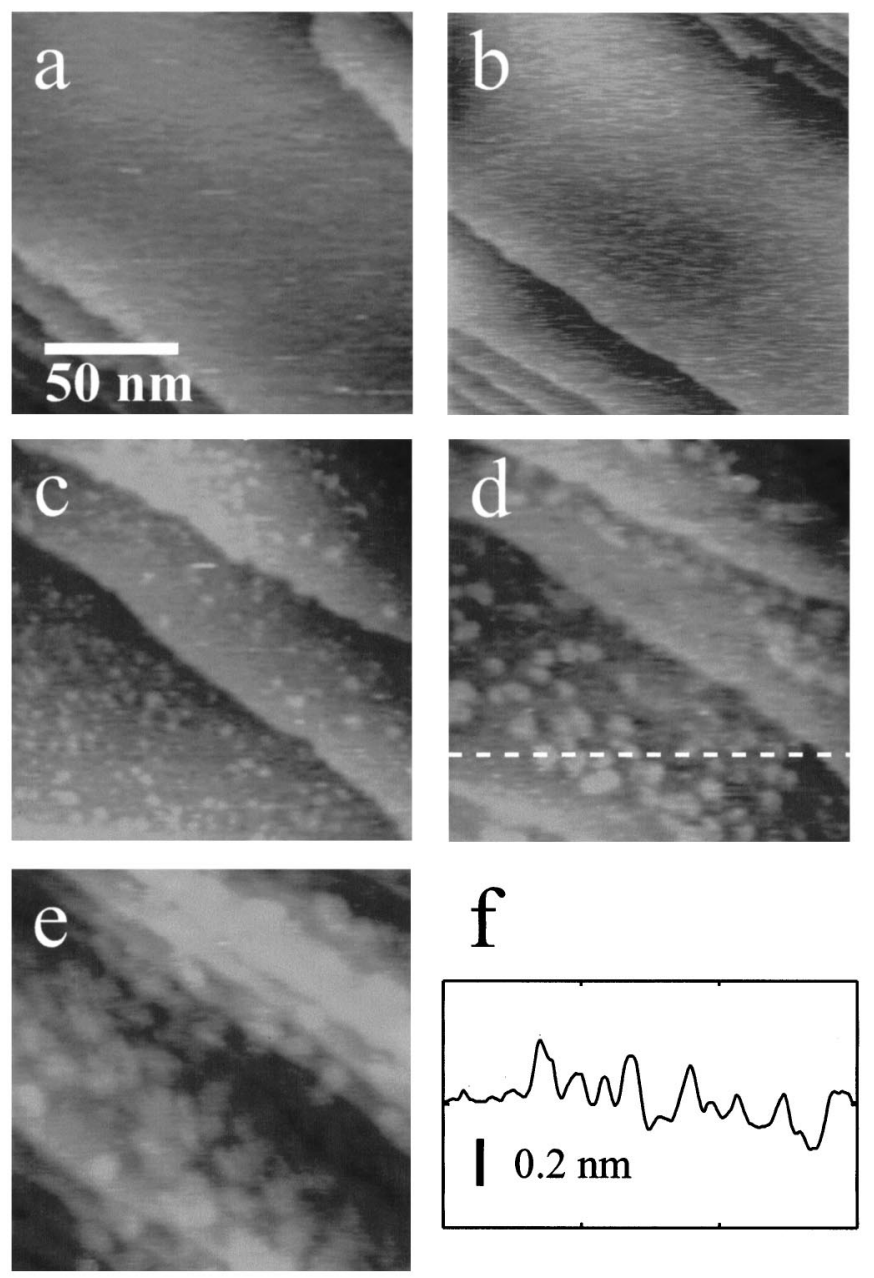

Figure 3. STM images $(150 \times 150 \mathrm{~nm})$ of $\mathrm{Au}(111)$ in a PC solution containing $0.1 \mathrm{M} \mathrm{LiClO}_{4}$ solution at $2.50 \mathrm{~V}$ (a) $7 \mathrm{~min}$, (b) $16 \mathrm{~min}$, (c) $30 \mathrm{~min}$, (d) $45 \mathrm{~min}$, and (e) $90 \mathrm{~min}$ after the injection of the PC solution. Cross section of (d) at a broken line is shown in (f). The tip potential was $2.0 \mathrm{~V}$ and the tunneling current was between 300 and 700 pA.

ringbone pattern. The herringbone structure is similar to the one observed at the reconstructed $\mathrm{Au}(111)$ surface, i.e., the $\sqrt{3} \times 22$ structure. ${ }^{42,43}$ While the typical width of the paired stripe of the $\sqrt{3}$ $\times 22$ structure observed on the reconstructed $\mathrm{Au}(111)$ surface is 6.3 $\mathrm{nm}$ and a change in the direction of the rows takes place every $\sim 20$ $\mathrm{nm}$, the width of the paired row of the present result was $c a .10 \mathrm{~nm}$ and the interval of the direction change was $c a .50 \mathrm{~nm}$, i.e., nearly twice the well-known $\sqrt{3} \times 22$ structure of the reconstructed $\mathrm{Au}(111)$. This structure was stable and remained for more than several hours at this potential.

Figure 5a shows an STM image captured at $1.90 \mathrm{~V} 30 \mathrm{~min}$ after the injection of the solution at this potential. The herringbone structure was also found on the terrace at this potential, although it was more ambiguous than at the pzc. The dimensions of the herringbone were almost equal to that at the pzc. Some holes, which were not observed at the pzc, were found on the terraces at this potential. They were always located on the wide dark stripe of the herringbone and their depth was $c a .0 .1 \mathrm{~nm}$ as shown in the cross section of the STM image (Fig. 5b). It should be noted that no hole was found on the terraces during the first STM scan. When a certain position was sequentially scanned, some holes were observed on the terraces from the second scan. Once the holes were formed during the second scan, the hole density did not increase in the following scans. 


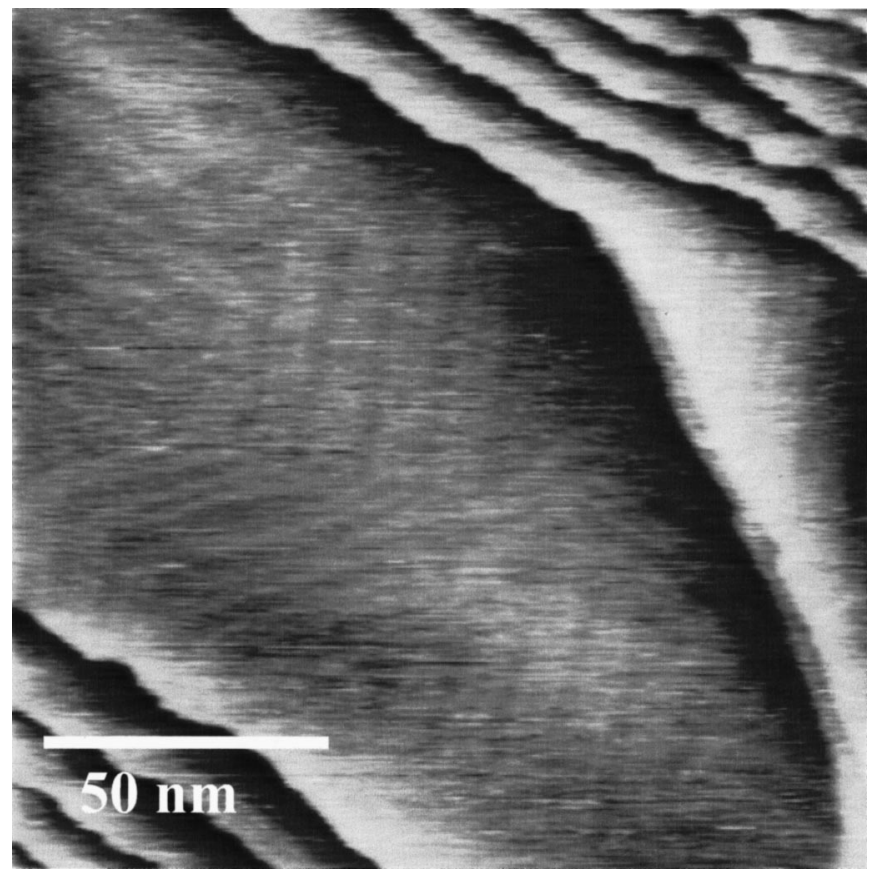

Figure 4. STM image $(150 \times 150 \mathrm{~nm})$ of $\mathrm{Au}(111)$ in a PC solution containing $0.1 \mathrm{M} \mathrm{LiClO}_{4}$ solution at $2.09 \mathrm{~V}$. The tip potential and tunneling current were $2.0 \mathrm{~V}$ and $380 \mathrm{pA}$, respectively.

Figure 6 shows the time-dependent STM images of the gold surface at almost the same position after the potential was stepped from $2.50 \mathrm{~V}$, i.e., more positive than the pzc, to $2.00 \mathrm{~V}$, i.e., more negative than the pzc. The $\mathrm{Au}(111)$ surface was initially covered with the island-like structure, which was at $2.50 \mathrm{~V}$ as mentioned before (Fig. 3). The potential was stepped to $2.00 \mathrm{~V}$ as indicated by the broken line in Fig. 6a. The scan direction of Fig. 6a is upward and there is no transition of the island-like structures just after the potential step (upper part of Fig. 6a). The island-like structure remained on the surface even 2 min after the potential step (Fig. 6b) but parts of the island-like structure seemed to combine with each other. The island-like structure became unclear 9 min after the potential step (Fig. 6c). It completely disappeared $16 \mathrm{~min}$ after the potential step, leaving a smooth terrace (Fig. 6d) as was observed when PC was injected while keeping the potential more negative than the pzc (Fig. 5). Figures $6 \mathrm{c}$ and d show that the disappearance of the island-like structure seemed to be accompanied with the structural change of the upper terrace. The sharp vertex at the corner of the triangular terrace in the lower right part of the STM images (Fig. $6 \mathrm{a}, \mathrm{b})$ became slightly round (Fig. 6c) and then significantly round (Fig. 6d) while the island-like structures were disappearing.

STM observation in neat PC.-After the flat terraces of the $\mathrm{Au}(111)$ were confirmed in the Ar atmosphere (Fig. 7a), neat PC was injected into the STM cell and then, the STM images were obtained sequentially (Fig. 7b-e). Several island-like nuclei were observed on the terrace $30 \mathrm{~min}$ after the injection of neat PC as shown in Fig. 7b. As time passed, the number of the island-like nuclei increased and the nuclei grew and merged with each other. The terraces were covered with these island-like structures after several tens of minutes (Fig. 7c-e). The heights of these structures on the $\mathrm{Au}(111)$ terrace were distributed between 0.15 and $0.3 \mathrm{~nm}$ as shown in the cross section of Fig. 7c (Fig. 7f). No significant difference in the nucleation density was observed between the step edge and terrace, and there was no specific direction for the growth of the island-like nuclei. The features of the island-like nuclei in neat PC such as size, growth rate, and distribution on the terrace were similar to those of the island-like nuclei in the PC solution containing $0.1 \mathrm{M} \mathrm{LiClO}_{4}$ at $2.5 \mathrm{~V}$.
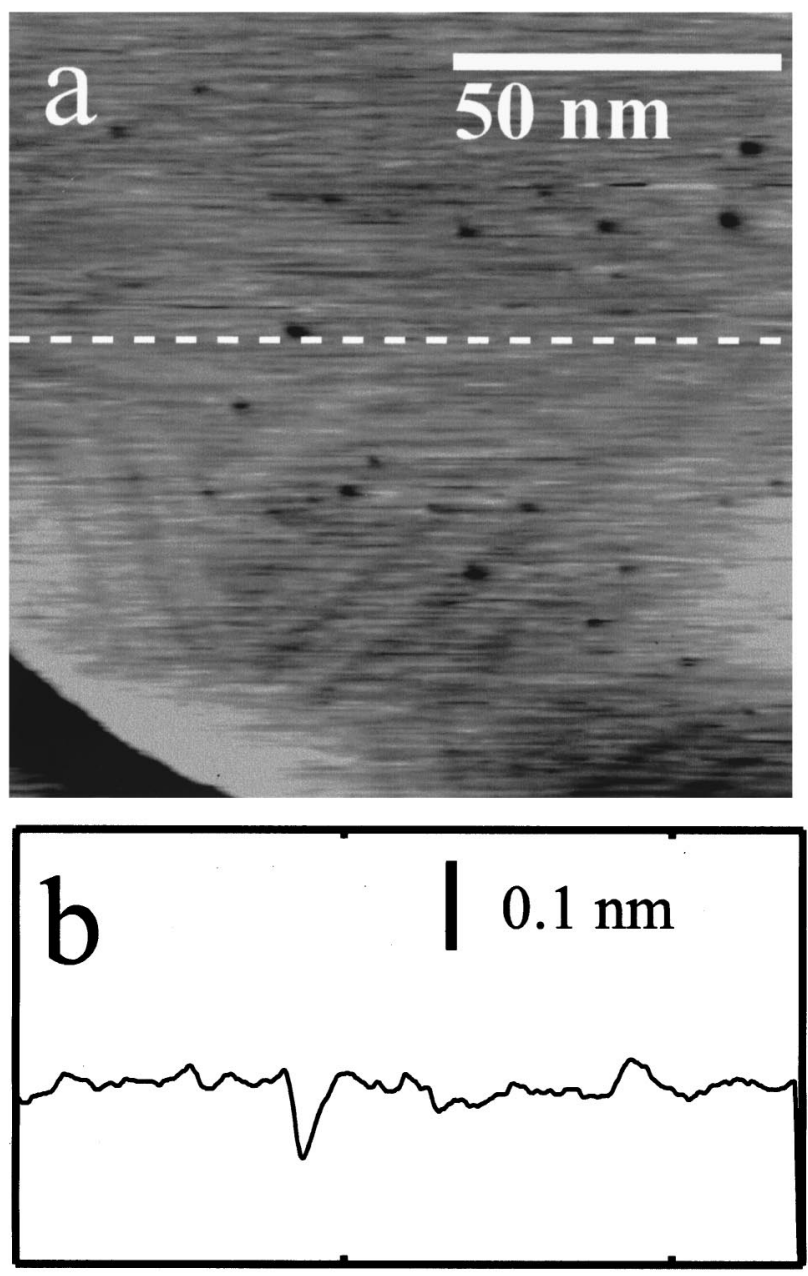

Figure 5. STM images $(120 \times 120 \mathrm{~nm})$ of $\mathrm{Au}(111)$ in a PC solution containing $0.1 \mathrm{M} \mathrm{LiClO}_{4}$ solution at $1.90 \mathrm{~V}$. The tip potential and tunneling current were $2.0 \mathrm{~V}$ and $290 \mathrm{pA}$, respectively.

\section{Discussion}

The time-dependent STM images observed at $2.50 \mathrm{~V}$ in a PC solution containing $0.1 \mathrm{M} \mathrm{LiClO}_{4}$ solution (Fig. 3) suggest the existence of an adsorbate layer. As the island-like structure of similar dimensions and growth rate was also observed in neat PC (Fig. 7), where the possible adsorbate is only the PC molecule, the island-like structure observed both in the neat PC and in the electrolyte solution should consist of PC molecules. Although an anion may adsorb on the electrode surface, the facts that $\mathrm{ClO}_{4}^{-}$does not adsorb on gold in aqueous solution ${ }^{41}$ and no specific adsorption of $\mathrm{ClO}_{4}^{-}$on a $\mathrm{Ag}$ electrode in $\mathrm{PC}$ solution was observed ${ }^{44}$ suggest that $\mathrm{ClO}_{4}^{-}$anion does not adsorb on the gold surface in PC. This is in good agreement with the STM observations.

The herringbone structure was observed for more than several hours at the pzc (2.09 V, Fig. 4) as well at potentials more negative than the pzc (Fig. 5). The existence of hole on the terraces (Fig. 5) and the deformation of the terrace (Fig. 6) at potentials more negative than the pzc suggest that the gold surface is covered by an adsorbate layer in this potential region. Usually, the coverage of neutral organic molecules on an electrode reaches a maximum at the pzc, because the surface charge of the electrode disappears and the electrostatic interaction between ions and the electrode became minimal at the pzc. In the present case, the neutral organic molecule in the electrolyte solution is the solvent itself. We already reported that a $\sqrt{3} \times 22$ structure of reconstructed $\mathrm{Au}(111)$ surface is ob- 

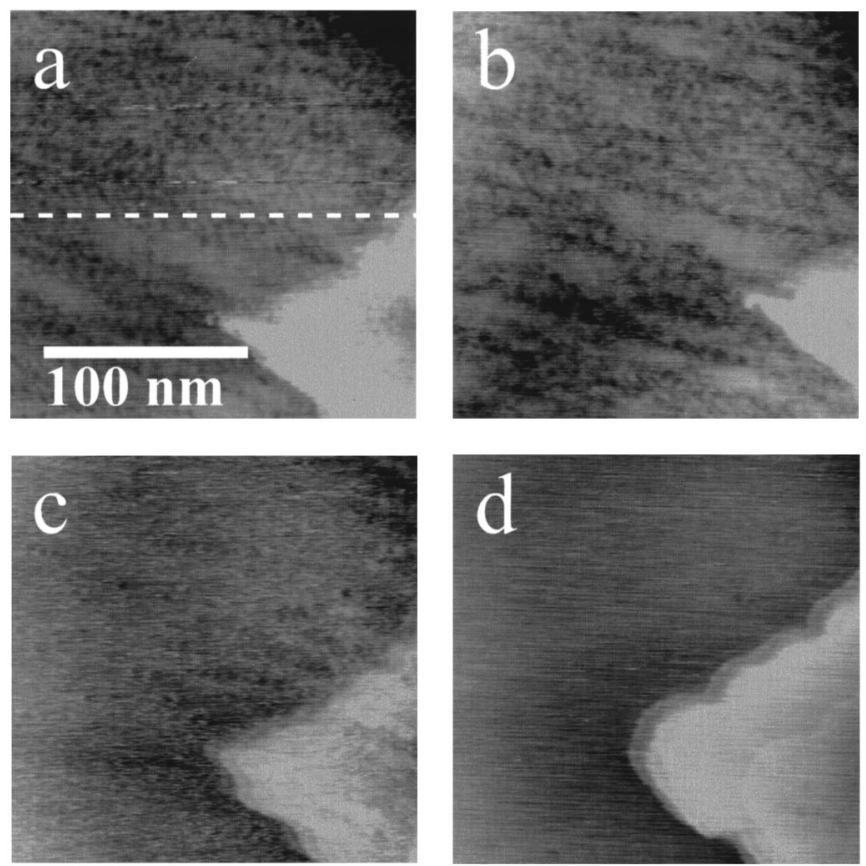

Figure 6. STM images $(200 \times 200 \mathrm{~nm})$ of $\mathrm{Au}(111)$ in a PC solution containing $0.1 \mathrm{M} \mathrm{LiClO}_{4}$ solution. The initial potential was $2.50 \mathrm{~V}$ and the potential was stepped from 2.50 to $2.00 \mathrm{~V}$ at the broken line in (a) where the scan direction was upward. (b) $2 \mathrm{~min}$, (c) $9 \mathrm{~min}$, and (d) $16 \mathrm{~min}$ after the potential step. The tip potential and tunneling current were $2.4 \mathrm{~V}$ and 400 $\mathrm{pA}$, respectively.

served by STM beneath the adsorbate layer of an alkane in neat alkane. This result shows that reconstruction of $\mathrm{Au}(111)$ can be retained under the adsorption of an organic molecule. ${ }^{25}$ In the present case, the width of the paired row of the reconstructed surface was $60 \%$ greater than that of the well-known $\sqrt{3} \times 22$ structure. Expansion of the reconstruction structure of $\mathrm{Au}(111)$ caused by $\mathrm{CO}$ adsorption was observed by surface X-ray diffraction at $20^{\circ} \mathrm{C}$ or higher temperature in an $\mathrm{Ar}$ atmosphere with the $\mathrm{CO}$ pressure of several hundreds mbar. ${ }^{45}$ Thus, the adsorption of PC molecules seemed to relax the surface stress and slightly expand the reconstruction structure in contrast to the adsorption of an alkane that did not change the dimensions of the reconstruction structure. This suggests that the interaction between PC and gold surface is stronger than that between an alkane and the gold surface, although a more detailed investigation is required to understand the nature of the interaction between PC and the gold surface.

The fact that holes were observed only at the wide dark stripe of the herringbone patterns and only after the STM scans suggests that the hole position reflected the difference in the adsorption strength. Although it is impossible to specify the exact registry of the surface atom as the width of the double row observed here, $60 \%$ larger than that of the typical reconstruction pattern of $\mathrm{Au}(111)$, it is reasonable to consider that the wide dark stripe corresponds to the face centered cubic (fcc) site based on the similarity to the well-known $\sqrt{3}$ $\times 22$ reconstruction pattern. According to a surface state calculation using the Kronig-Penny potential and STS measurement of the $\mathrm{Au}(111)$ surface in ultrahigh vacuum, a surface state exists $0.5 \mathrm{eV}$ below the Fermi level at the hexagonal close packed (hcp) site. ${ }^{46}$ This means the electron densities at the hcp site are higher than that at the fcc site. If this is also valid in the PC solution, the position of the holes agrees with the low electron density site of the $\mathrm{Au}(111)$ reconstructed surface. Thus, the nonuniform distribution of the electron density on the $\mathrm{Au}(111)$ surface seems to cause the difference in the adsorption strength and adsorbed molecule at the fcc site were easily to be abstracted by the STM tip, resulting in the formation of
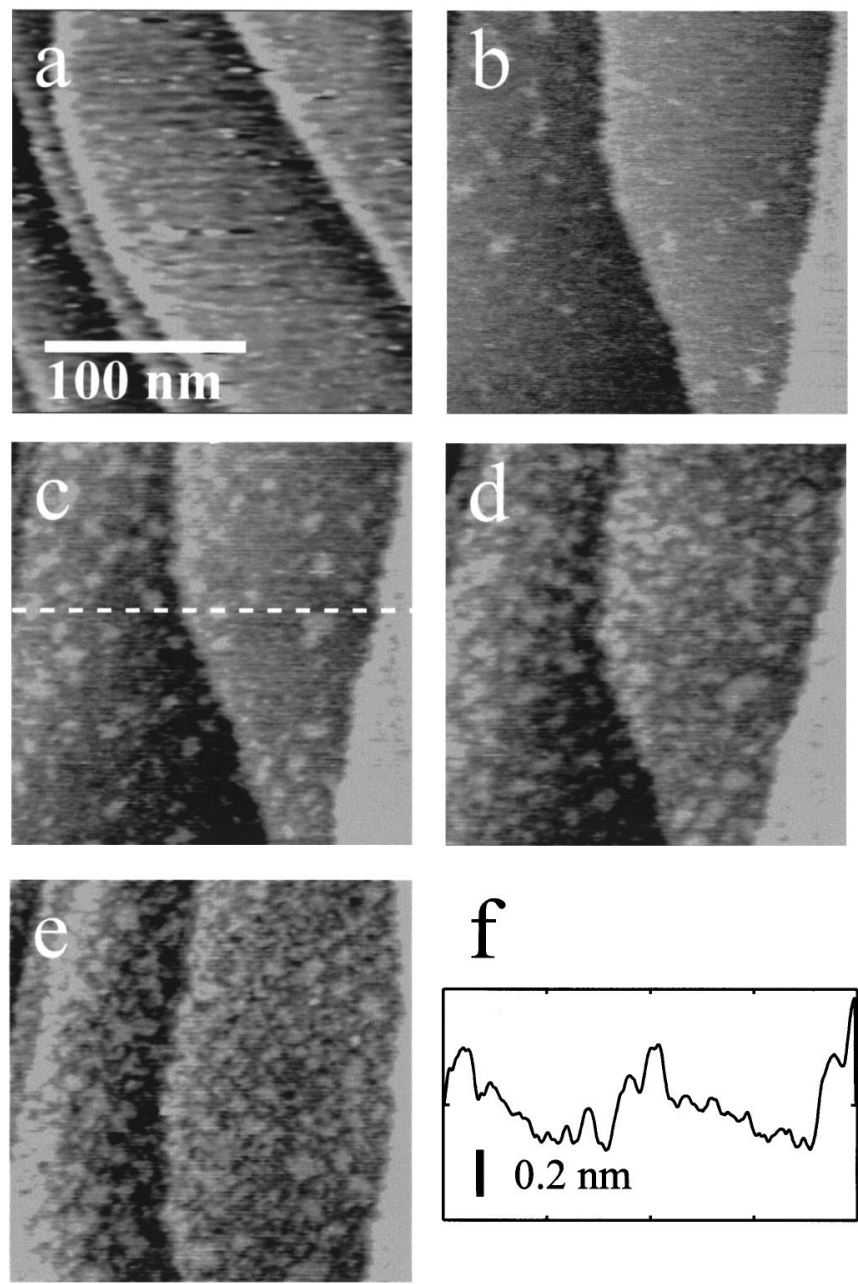

Figure 7. STM images $(200 \times 200 \mathrm{~nm})$ of $\mathrm{Au}(111)$ (a) before and (b) 30 min, (c) $45 \mathrm{~min}$, (d) $60 \mathrm{~min}$, and (e) $85 \mathrm{~min}$ after the injection of neat PC. A cross section of (c) at a broken line is shown in (f). The tip potential and tunneling current were $100-500 \mathrm{mV}$ and 140-750 pA, respectively.

holes. Although the depth of holes does not fit to any dimensions of PC molecule, a Z-scale of the STM image, however, reflects not only the geometrical depth but also the difference in electronic states of the PC molecule/gold surface.

No change in the step edge was observed in the STM observation at a constant potential but when the electrode potential was stepped from 2.50 to $2.00 \mathrm{~V}$ (Fig. 6), the deformation of the step edge was observed while the island-like structures were disappearing. As the coverage of the adsorbate decreased when the potential was stepped from 2.50 to $2.00 \mathrm{~V}$, the excess adsorbed PC molecules should be dissolved into the solution but some of them seemed to move from the terrace to the step edge, resulting in the shape change in the step edge.

\section{Conclusion}

An adsorbate layer on the $\mathrm{Au}(111)$ surface in a PC solution containing $0.1 \mathrm{M} \mathrm{LiClO}_{4}$ was found by STM observations. A structural change in the adsorbate layer depending on the electrode potential was observed. An island-like structure was observed at potentials more positive than the pzc and it seemed to be same as the adsorbate layer observed in neat PC solution. The similarity in the STM images in both solutions suggests that these adsorbate layers have the same composition and structure. At the pzc, a surface reconstruction structure of the $\mathrm{Au}(111)$ surface was observed and at potentials more negative than the pzc, small holes in the reconstruction pattern were 
observed. These results suggest the existence of a thin film of almost uniform thickness, and this adsorbate was thought to be the PC molecule. The position of the holes at the more negative potentials was thought to correspond to the position at which electron density is lower than the other places. As described above, the adsorbate on the gold surface was expected to be the PC molecule at any potential and the structural change was caused by an electrostatic interaction between the surface charge of the electrode and dipole moment of the PC molecule. It has been speculated that the surface film on the electrode plays important roles for the Li deposition, although the details of the film are not known. In this paper, we showed how the surface film is formed. We are now investigating how the surface film affects the lithium deposition/desorption processes by in situ STM.

\section{Acknowledgment}

This work is partially supported by a Grand-in-Aid for Scientific Research (13554026) from the Ministry of Education, Culture, Sports, Science and Technology, Japan.

Hokkaido University assisted in meeting the publication costs of this article.

\section{References}

1. E. Peled, J. Electrochem. Soc., 126, 2047 (1979).

2. D. Aurbach, in Nonaqueous Electrochemistry, D. Aurbach, Editor, p. 289, Marcel Dekker, New York (1999).

3. D. Aurbach, M. L. Daroux, P. W. Faguy, and E. Yeager, J. Electrochem. Soc., 134, 1611 (1987)

4. D. Aurbach, J. Electrochem. Soc., 136, 1606 (1989)

5. D. Aurbach, J. Electrochem. Soc., 136, 1611 (1989).

6. Y. Gofer, Y. E. Ely, and A. Aurbach, Electrochim. Acta, 37, 1897 (1992).

7. D. Aurbach, M. L. Daroux, P. W. Faguy, and E. B. Yeager, J. Electrochem. Soc., 135, 1863 (1988).

8. K. Kanamura, S. Shiraishi, H. Tamura, and Z. Takehara, J. Electrochem. Soc., 141, 2379 (1994)

9. K. Kanamura, H. Tamura, S. Shiraishi, and Z. Takehara, J. Electrochem. Soc., 142 340 (1995).

10. K. Kanamura, H. Tamura, S. Shiraishi, and Z. Takehara, Electrochim. Acta, 40, 913 (1995)

11. K. Kanamura, H. Tamura, and Z. Takehara, J. Electroanal. Chem., 333, 127 (1992),

12. A. A. Gewirth and B. K. Niece, Chem. Rev., 97, 1129 (1997).

13. K. Uosaki, S. Ye, H. Naohara, Y. Oda, T. Haba, and T. Kondo, J. Phys. Chem. B, 101, 7566 (1997).
14. H. Naohara, S. Ye, and K. Uosaki, J. Phys. Chem. B, 102, 4366 (1998).

15. H. Naohara, S. Ye, and K. Uosaki, J. Electroanal. Chem., 473, 2 (1999).

16. H. Naohara, S. Ye, and K. Uosaki, Colloids Surf., A, 154, 201 (1999).

17. M. Takahasi, Y. Hayashi, J. Mizuki, K. Tamura, T. Kondo, H. Naohara, and K. Uosaki, Surf. Sci., 461, 213 (2000).

18. M. Koinuma and K. Uosaki, Electrochim. Acta, 40, 1345 (1995).

19. S. Ye, C. Ishibashi, and K. Uosaki, Langmuir, 15, 807 (1999).

20. S. Ye, C. Ishibashi, and K. Uosaki, in Scanning Probe Techniques for Materials Characterization at Nanometer Scale, D. C. Hansen, H. S. Isaacs, and K. Sieradzki, Editors, PV 2000-35 p. 133, The Electrochemical Society Proceedings Series, Pennington, NJ (2001).

21. R. Yamada and K. Uosaki, Langmuir, 13, 5218 (1997).

22. R. Yamada and K. Uosaki, Langmuir, 14, 855 (1998).

23. K. Uosaki and R. Yamada, J. Am. Chem. Soc., 121, 4090 (1999).

24. R. Yamada and K. Uosaki, Langmuir, 16, 4413 (2000).

25. R. Yamada and K. Uosaki, J. Phys. Chem. B, 104, 6021 (2000).

26. D. Aurbach and Y. Cohen, J. Electrochem. Soc., 143, 3525 (1996).

27. D. Aurbach and Y. Cohen, J. Electrochem. Soc., 144, 3355 (1997).

28. D. Aurbach and Y. Cohen, Electrochem. Solid-State Lett., 2, 16 (1999).

29. Handbook of Chemistry and Physics, p. 3, D. R. Lide, Editor, CRC, Boca Raton, FL (1994).

30. W. J. Peppel, Ind. Eng. Chem., 50, 768 (1958).

31. D. Aurbach and Y. Gofer, in Nonaqueous Electrochemistry, D. Aurbach, Editor, p. 139, Marcel Dekker, New York (1999).

32. D. Aurbach, Y. Gofer, M. Ben-Zion, and P. Aped, J. Electroanal. Chem., 339, 451 (1992).

33. D. Aurbach and A. Zaban, J. Electroanal. Chem., 393, 43 (1995).

34. Y. S. Cohen, Y. Cohen, and D. Aurbach, J. Phys. Chem. B, 104, 12282 (2000).

35. K. Kanamura, S. Shiraishi, and Z. Takehara, J. Electrochem. Soc., 141, L108 (1994).

36. K. Kanamura, S. Shiraishi, and Z. Takehara, J. Electrochem. Soc., 143, 2187 (1996)

37. R. D. Rauh and S. B. Brummer, Electrochim. Acta, 22, 75 (1977).

38. J. G. Thevenin and R. H. Muller, J. Electrochem. Soc., 134, 273 (1987).

39. D. Aurbach, M. Daroux, P. Faguy, and E. Yeager, J. Electroanal. Chem., 297, 225 (1991).

40. J. Clavilier, J. Electroanal. Chem., 107, 211 (1980).

41. A. J. Bard and L. R. Faulkner, in Electrochemical Methods, p. 553, John Wiley \& Sons, New York (2001).

42. M. H. Dishner, J. C. Hemminger, and F. J. Feher, Langmuir, 13, 2318 (1997).

43. C. Wöll, S. Chiang, R. J. Wilson, and P. H. Lippel, Phys. Rev. B, 39, 7988 (1989).

44. I. R. Hill, D. E. Irish, and G. F. Atkinson, Langmuir, 2, 752 (1986).

45. K. F. Peters, P. Steadman, H. Isern, J. Alvarez, and S. Ferrer, Surf. Sci., 467, 10 (2000).

46. W. Chen, V. Madhavan, T. Jamneala, and M. F. Crommie, Phys. Rev. Lett., 80, 1469 (1998) 